\title{
CONSERVAÇÃO DO SOLO NA HORTICULTURA DAS REGIÕES DE NOVA FRIBURGO (BRASIL) E BUENOS AIRES (ARGENTINA)
}

\author{
SOIL CONSERVATION IN HORTICULTURE IN THE REGIONS OF NOVA \\ FRIBURGO (BRAZIL) AND BUENOS AIRES (ARGENTINA)
}

\section{CONSERVACIÓN DE SUELOS EN HORTICULTURA EN LAS REGIONES DE NOVA FRIBURGO (BRASIL) Y BUENOS AIRES (ARGENTINA)}

\author{
Ricardo Edson Salles ${ }^{1}$ \\ https://orcid.org/0000-0002-8659-3809 \\ Renato Linhares de Assis ${ }^{2}$ \\ https://orcid.org/0000-0003-4228-5166 \\ Adriana Maria de Aquino ${ }^{3}$ \\ https://orcid.org/0000-0003-3718-4512
}

Submissão: 27/01/2021 / Aceito: 23/09/2021 / Publicado: 04/02/2022.

\begin{abstract}
Resumo
A horticultura é atividade dinâmica e intensa, em que o manejo da matéria orgânica do solo é fundamental. Apresenta-se análise desse manejo com a inserção de plantas de cobertura de solo nas rotações de cultivo de hortaliças em Nova Friburgo (Brasil) e Buenos Aires (Argentina). Isso a partir de estudo de caso com entrevistas de agricultores selecionados com amostragem não probabilística realizada a partir da indicação por atores-chave nos dois países, dos que tivessem experiência consolidada com a temática analisada. Verificouse nos dois locais que aveia preta era a planta mais utilizada e que isso se devia a ação de técnicos de instituições públicas, porém, não havia planejamento rotineiro das rotações de cultivo para que houvesse o pré-cultivo de plantas de cobertura de solo ao menos uma vez ao ano em todas as áreas de produção. Nas duas regiões estudadas havia pouca oferta de sementes no comércio de insumos, em quantidade e diversidade que favorecesse a prática em questão rotineiramente, inclusive com o uso de maior número de espécies vegetais. As dinâmicas produtivas analisadas têm dilemas correlatos que demandam ações governamentais e políticas públicas específicas, que apoiem o desenvolvimento e disseminação de soluções que visem melhorar sua sustentabilidade.
\end{abstract}

Palavras-chave: Plantas de cobertura de solo. Agricultura familiar. Transferência de tecnologia.

\footnotetext{
Abstract

Horticulture is a dynamic and intense activity, in which the management of the soil's organic matter is essential. The analysis of this management is presented from the insertion

${ }^{1}$ Doutor em Ciência, Tecnologia e Inovação em Agropecuária pela Universidade Federal Rural do Rio de Janeiro - área de concentração Agrobiologia. Consultor autônomo. E-mail: ricardosalles2011@ gmail.com. ${ }^{2}$ Doutor em Economia Aplicada - área de concentração Desenvolvimento Econômico, Espaço e Meio Ambiente pela Universidade Estadual de Campinas. Pesquisador da Embrapa Agrobiologia. E-mail: renato.assis@embrapa.br.

${ }^{3}$ Doutora em Agronomia - área de concentração Ciência do Solo pela Universidade Federal Rural do Rio de Janeiro. Pesquisadora da Embrapa Agrobiologia. E-mail: adriana.aquino@embrapa.br.
} 
of soil cover plants in the crop rotation of vegetables in family production systems in Nova Friburgo, (Brazil) and Buenos Aires (Argentina). This was based on a case study from interviews with a non-probabilistic sampling of farmers nominated by key actors in both countries, which have consolidated experience with soil cover plants. It was verified in both that black oats were the most used plant, due to the action of technicians from public institutions, however, there was no routine planning of these rotations so that there was the pre-cultivation of soil cover plants at least once a year in all production areas. In the two studied regions, there was little supply of seeds in the trade of inputs, in quantity and diversity that favored the practice more routinely by farmers, including the use of a greater number of plant species. The dynamics of production analyzed have related dilemmas that demand specific government actions and public policies, which support the development and dissemination of solutions that aim at improving their sustainability.

Keywords: Soil cover plants. Family agriculture. Transfer of technology.

\section{Resumen}

La horticultura es una atividade dinámica e intensa, em la que el manejo de la matéria orgânica del suelo es fundamental. Se presenta un análisis de este manejo con la inserción de plantas de cobertura del suelo en las rotaciones de cultivo de hortalizas en Nova Friburgo (Brasil) y Buenos Aires (Argentina). Esto con un estudio de caso con entrevistas a agricultores con experiencia consolidada con el tema, seleccionados con muestros no probabilísticos realizado a partir de indicaciones de actores clave en los dos países. Se encontró en ambas localidades que la avena negra era la planta más utilizada y que esto se debió a la acción de técnicos de instituciones públicas, sin embargo, no existia precultivo de plantas de cobertura del suelo al menos una vez al año en todas las áreas de producción. En ambos lugares había poca oferta de semillas en el comercio de insumos, en cantidad y diversidade que favoreceria habitualmente la práctica en cuestión, incluído el uso de un mayor número de especies vegetales. Las dinâmicas productivas analizadas tiene dilemas relacionados que demandan acciones de gobierno y políticas públicas específicas, que apoyen el desarrollo y difusión de soluciones orientadas a mejorar su sostenibílidad.

Palabras chave: Plantas de cobertura del suelo. Agricultura familiar. Transferencia tecnológica.

\section{INTRODUÇÃO}

Projetos de horticultura, particularmente por questões de logística, entre outras, tendem a se instalarem em áreas próximas a grandes centros urbanos, constituindo territórios de importância social significativa em que a ocupação, em sua maioria, é da agricultura familiar. Módulos de produção com dimensionamento reduzido, aliado ao manejo intensivo, são fatores que influenciam para a ocorrência de iniciativas geradoras de impactos ambientais negativos. O uso de plantas de cobertura de solo, ao ser incorporado de forma sistemática nessas áreas de produção, possibilita uma abordagem mais sustentável 
à produção de hortaliças (ALTIERI et al., 2012; ANTONIO et al., 2019; SILVA HIRATA et al., 2009), podendo proporcionar melhores resultados de produção, como observado no cultivo de tomate em Santa Catarina por Valmorbida et al. (2002).

O uso de plantas de cobertura de solo nas rotações de cultivo de hortaliças apresenta potencial para melhoria da eficiência agronômica e ambiental dos agroecosistemas (ANGELETTI, 2016). Verifica-se isto em decorrência dos efeitos físico, químico e biológico benéficos ao solo que essa prática proporciona, bem como pela sua contribuição para a supressão de plantas espontâneas, podendo até eliminar a necessidade de aplicação de herbicidas (SILVA HIRATA et al., 2009).

Antonio et al. (2019) descrevem relatos de agricultores familiares produtores de hortaliças sobre a melhoria da qualidade do solo com uso de plantas de cobertura, percebida pela observação de uma maior abundância de raízes e da macrofauna edáfica, bem como equilíbrio no teor de umidade dos solos, com consequente economia na irrigação. Os autores descrevem ainda relatos de benefícios fitossanitários, com destaque para a redução da hérnia das crucíferas em cultivos de couve flor, assim como Silva Hirata et al. (2009) relataram redução de perdas em tomateiro decorrentes de podridões, enfatizando a importância do uso de plantas de cobertura de solo para a sustentabilidade dessa cultura. Segundo Redin et al. (2016) existem diversas tecnologias agroecológicas apropriadas para o correto manejo do solo, destacando a importância do uso de plantas de cobertura de solo para a boa qualidade biológica do solo. Enquanto que Grisel e Assis (2020), ao destacarem a importância de práticas agroecológicas para a sustentabilidade, enfatizam que a adoção destas deve ser gradual, respeitando o tempo dos agricultores de forma que tenham condições de ajustar as mudanças à dinâmica de seus agroecossitemas.

Este artigo tem por objetivo analisar o processo de inserção de plantas de cobertura de solo em rotações de cultivo de hortaliças em sistemas de produção familiares no Brasil e na Argentina. No Brasil a escolha do município de Nova Friburgo, foi em função da sua importância no cenário da horticultura nacional, caracterizado pelo segundo maior polo de produção hortícola do país, a Região Serrana Fluminense, sendo o município, com base na produção familiar, o maior produtor brasileiro de couve flor (ASSIS; AQUINO, 2010). Na Argentina a escolha foi da área metropolitana de Buenos Aires (AMBA), que abriga grande cinturão verde que abastece com hortaliças a principal área urbana do país, também com forte atividade de produção familiar (LE GALL; GARCÍA, 2010). 


\section{Procedimentos metodológicos}

A pesquisa teve caráter quali-quantitativo, descritivo, realizada a partir de estudo de caso conforme Yin (2001), com o uso de questionário semiestruturado para a realização de entrevistas, buscando estudar a prática do uso de plantas de cobertura de solo e o processo de sua disseminação nas rotações de cultivo de hortaliças dos sistemas de produção familiares analisados.

Os dois locais de estudo foram selecionados em função de se ter informações anteriores acerca de experiências consolidadas do uso de plantas de cobertura de solo em sistemas de produção familiares com cultivo de hortaliças, aliado a disponibilidade de estrutura de apoio para realização da pesquisa.

Assim, o trabalho nos dois países iniciou-se com a solicitação a atores-chave da indicação de agricultores com dinâmica produtiva em que houvesse o uso de plantas de cobertura de solo em suas rotações de cultivo de hortaliças, de forma a constituir amostra não probabilística de experiências consolidadas com a prática em questão. O que possibilitou, no Brasil, a constituição de um grupo de 15 agricultores familiares produtores de hortaliças no município de Nova Friburgo, que foram entrevistados em maio de 2016. Por sua vez, na Argentina, constituiu-se um grupo de 12 agricultores familiares, localizados nos municípios de Ituzaingó, La Matanza, Morón, Moreno e Escobar, que foram entrevistados em julho de 2016.

Buscou-se caracterizar a relação dos agricultores com a terra, destacando o sentimento acerca do impacto e importância do uso das plantas de cobertura de solo em seus sistemas produtivos, o grau de satisfação com a funcionalidade da prática no tocante ao gerenciamento de suas atividades operacionais e benefícios ao solo e a produção.

A ênfase foi para as questões que motivaram e determinaram a adoção do uso de plantas de cobertura de solo, as formas de manejo adotadas, e quais indicadores da qualidade do solo e do manejo eram mais proeminentes e percebidos pelos agricultores, com destaque para: (i) aspectos sanitários (solo e planta); (ii) eficiência da irrigação; (iii) manejo de espécies de plantas espontâneas; (iv) erosão do solo; e (vi) gerenciamento da produção. 
O processo de coleta de informações ocorreu com clima de informalidade nas unidades de produção dos agricultores, de forma a estabelecer ambiente em que estes estivessem à vontade para se expressar e manifestar suas opiniões.

\section{USO de Plantas de COBERTURA de SOlo POR HORTICUltores de NOVA Friburgo - RJ (BRASIL)}

Todos os agricultores das 15 unidades de produção visitadas em Nova Friburgo tinham experiência com o uso de plantas de cobertura do solo, dentre esses, três que atuavam prioritariamente em mercado local, não utilizavam agroquímicos sintéticos e estavam alinhados ao manejo agroecológico, com destaque para um deles que possuía selo orgânico de produção. Os demais (12) manejavam suas unidades de produção de forma convencional, produzindo em larga escala para atender prioritariamente a demanda por hortaliças do mercado da região metropolitana da cidade do Rio de Janeiro, com destaque para brássicas e tomate.

Verificou-se que a experiência dos agricultores entrevistados com plantas de cobertura estava praticamente restrita ao uso de aveia preta (Avena strigosa). Isso devido, conforme os relatos, pelo fato desta ter como período ideal para cultivo na região o inverno, quando os preços das hortaliças são menos favoráveis aos agricultores e há maior disponibilidade de áreas para o cultivo da planta de cobertura em questão.

A recomendação técnica de época ideal para o plantio de aveia preta na região é o mês de junho, enquanto que o momento indicado para o corte da planta, de forma a obter o máximo rendimento de produção de massa vegetal, é o que se denomina como de "grão leitoso", que é quando a planta atinge seu máximo desenvolvimento vegetativo (BARRADAS et al., 2001). Porém, verificou-se que isso era feito pelos agricultores em um período estendido de março a novembro, e o manejo do cultivo como planta de cobertura ocorria em diferentes momentos do seu desenvolvimento vegetativo, em função das demandas por área para os cultivos comerciais nas unidades de produção.

Esse manejo ocorria de diferentes formas: (i) deixavam a planta tombar naturalmente; (ii) utilizavam herbicida para dessecar; ou (iii) cortavam mecanicamente com roçadeira ou triturador. Dependendo da época do ano e do tipo de hortaliça a ser cultivada 
na sequência cultural, a palhada era deixada na superfície ou incorporada no solo mecanicamente.

No caso da couve flor, a estratégia utilizada era o pré-cultivo de aveia preta semeada no início do período de menor incidência de chuvas (inverno), de forma que o preparo do solo já fosse o definitivo e suficiente, para o cultivo da planta de interesse comercial no período de maior incidência de chuvas (verão), sem necessidade de nova movimentação de solo, que era mantido coberto com a palhada da aveia preta (Figura 2).

\begin{abstract}
“[...] preparamos o solo e a aveia é semeada e incorporada mecanicamente. Fazemos a adubação química antes para o plantio de couve flor. Na época certa é feita a aplicação do herbicida, a gente tomba a aveia e depois vem plantando a couve flor [...]" (Agricultor B1).
\end{abstract}

"[...] plantamos em terreno muito inclinado, então nós deixamos a aveia o ano todo como cobertura [...]. A erosão acabou [...]” (Agricultor B2).

Na Figura 1 é possível visualizar o manejo usual da aveia preta para o plantio da couve flor na região.

Figura 1. Aspectos da aveia preta após corte de pré-cultivo (A) e em área de produção de couve flor (B) em Nova Friburgo (RJ).
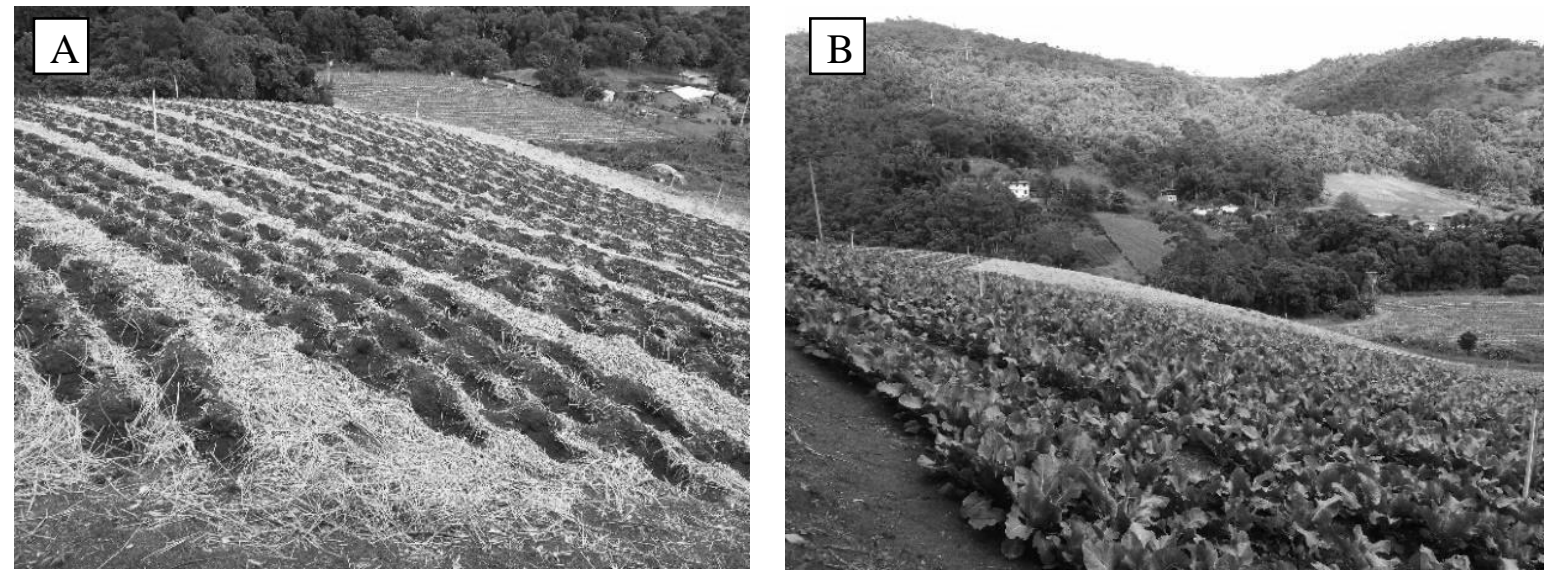

Fotos: Ricardo Edson Salles.

Um dos entrevistados declarou desenvolver práticas agroecológicas, com a minimização do uso de produtos industrializados (adubos sintéticos e agrotóxicos), tendo relatado que além da aveia preta utilizava como planta de cobertura de solo o tremoço branco (Lupinus albus), comentando sobre os benefícios que observou na plantação de aspargos, associados a essa espécie leguminosa que se associa a bactérias fixadoras de $\mathrm{N}_{2}$.

DOI: http://dx.doi.org/10.22295/grifos.v31i56.6034 | Edição Vol. 31, Núm. 56, 2022. 
“[...] plantamos aspargos que é uma cultura que acama muito devido ao hábito ascendente. Quando passei a usar o tremoço como cobertura nas entrelinhas, obtivemos $50 \%$ de redução no acamamento. Todo ano nós refazemos $50 \%$ da área com coberturas de solo, aveia principalmente, em rotação [...]" (Agricultor B3).

Com relação à saúde dos cultivos, da mesma forma que Antonio et al. (2019), verificou-se relatos que a aveia preta, quando utilizada de forma recorrente, auxiliava na redução da incidência da hérnia das crucíferas (Plasmodiophora brassicae) que comumente compromete a viabilidade econômica das lavouras de brássicas na região.

“[...] eu uso a aveia preta desde que começou aqui na região, e com o tempo dá para ver que a quantidade de hérnia diminuiu. Antes, em algumas áreas, a gente plantava e perdia [...]" (Agricultor B4).

Verificou-se ainda a importância da interação das instituições que atuavam na formação de jovens no meio rural de Nova Friburgo, para a disseminação da prática, como a realização de trabalhos conjuntos da Embrapa com o Centro Familiar de Formação por Alternância Rei Alberto I (CEFFA CEA Rei Alberto I), escola família agrícola da região, conforme expresso pelo pai de uma aluna:

“[...] passei a usar a aveia por causa da minha filha [...] que viu essa técnica [no colégio agrícola] [...]. Trouxe a novidade para mim e achei que melhorou [...]" (Agricultor B5).

Sobre o manejo de plantas espontâneas indesejáveis, assim como indicaram Silva Hirata et al. (2009), Angeletti et al. (2016) e Redin et al. (2016), verificou-se, na grande maioria dos relatos, que as plantas de cobertura do solo auxiliavam na supressão dessas plantas, diminuindo a frequência de capinas.

"[...] iniciamos com a aveia, experimentamos durante um tempo e depois paramos de usar, mas notamos que nas áreas com aveia houve uma maior quantidade de "beladoninha" ou "maria pretinha" plantas que fazem bem a lavoura [...]" (Agricultor B6). 


\section{USO DE PLANTAS DE COBERTURA DE SOLO POR HORTICUltores DA Área METropolitanA DE BUENOS AIRES - AMBA (ARgENTINA)}

Das 12 unidades de produção de hortaliças visitadas na Área Metropolitana de Buenos Aires (AMBA), quatro foram no município de La Matanza, duas no município de Morón, uma no município de Moreno, quatro no município de Escobar e uma em Ituzaingó. Desse universo, 10 unidades de produção pertenciam a argentinos natos que manejavam suas áreas agrícolas em bases agroecológicas sem o uso de insumos industriais, enquanto que as duas restantes eram de imigrantes de origem boliviana que manejavam sua produção, principalmente de folhosas em cultivo protegido, de forma convencional.

Os produtores entrevistados adotavam estratégias diversas de uso e manejo das plantas de cobertura do solo: (i) forração dos canteiros de hortaliças com massa vegetal de pastagem cortada no período de verão, quando esta vegetação é abundante e seu corte não compromete a alimentação da criação animal; (ii) manejo de plantas espontâneas no período de inverno; e (iii) inserção do plantio de plantas de cobertura de solo na rotação de cultivo de hortaliças.

Para o uso de plantas de cobertura de solo alguns agricultores declararam utilizar práticas ancestrais, como a produção e troca de sementes de variedades locais, cuja qualidade era mantida com cultivos anuais em que realizavam seleção massal das melhores plantas. Prática comum há mais de 50 anos por parte de $80 \%$ dos entrevistados.

"[...] las semillas de plantas de cobertura, son originarias de un largo trabajo, de intercambios [com outros agricultores] y cosechas sucessivas [...]" (Agricultor A1).

Em Morón havia o "Espaço Urbano da Agroecologia", que inserido no projeto Morón Surco, desenvolvido com apoio do Instituto Nacional de Tecnologia Agropecuária (INTA) e da Faculdade de Agronomia da Universidade de Buenos Aires, constituía proposta para promover a melhoria da qualidade de vida das famílias agricultoras, através da manutenção de atividades educacionais. No espaço em questão trabalhava-se a valorização do enriquecimento do solo com práticas agroecológicas de produção, entre essas o uso de plantas de cobertura para a conservação do solo. 
Para todos os agricultores entrevistados o uso de plantas de cobertura de solo era prioridade, e utilizavam estratégias e manejo com o plantio de plantas de cobertura que contribuíssem para o condicionamento do solo sem o uso de instrumentos mecânicos.

\begin{abstract}
“[...] en algunos lugares utilizamos solamente especies de cobertura para preparar el suelo. En el invierno plantamos el nabo forrajero, para descompactar los canteros, y luego la fava, en la plantación cubrimos el cantero con paja de alfalfa y avena, manteniendo la humedad, reponiendo a cada ciclo e incorporando ese material con el tempo [...]" (Agricultor A2).
\end{abstract}

Ainda no município de Morón, havia o trabalho da "Fundación La Choza" que, com atuação baseada nos preceitos da agricultura biodinâmica, desenvolvia atividades visando apoiar os agricultores no acesso a mercados específicos e diferenciados, notadamente venda direta para restaurantes, feiras e entregas em domicílio. O agricultor A3 descreveu a missão da instituição:

"[...] La Choza es una fundación, y pretendemos crear las condiciones para un trabajo social-pedagógico basado en una tierra y agricultura saludables, la armonía con el cosmos y la curación para hombres, animales y plantas. Actitudes que tienden a superar la brecha cultural creciente entre la ciudad y el campo $[\ldots] "$ (Agricultor A3).

No município de "Ituzaingó" de acordo com os relatos dos agricultores as plantas de cobertura de solo eram incorporadas ou deixadas sobre o solo (Figura 2), verificando-se que tinham percepção de que a prática possibilitava maior estabilidade no manejo da irrigação, reduzindo problemas com alagamento ou seca, devido a melhor infiltração da água e retenção da umidade no solo.

“[...] en primer lugar, plantamos una raíz para traer el suelo, generalmente el nabo forraje, o incluso la avena, entonces plantamos el maíz en el verano, y en invierno, la acelga combinado con la cebolla. Como las áreas son trabajadas manualmente, notamos que se hizo más fáceis y que la humedad mejoró [...]" (Agricultor A4). 
Figura 2. Aspectos do preparo do solo empregado pelos agricultores de Ituzaingó, com preparo manual após o uso de plantas de cobertura do solo (A) e cobertura dos canteiros com palhada de espécies espontâneas (B).
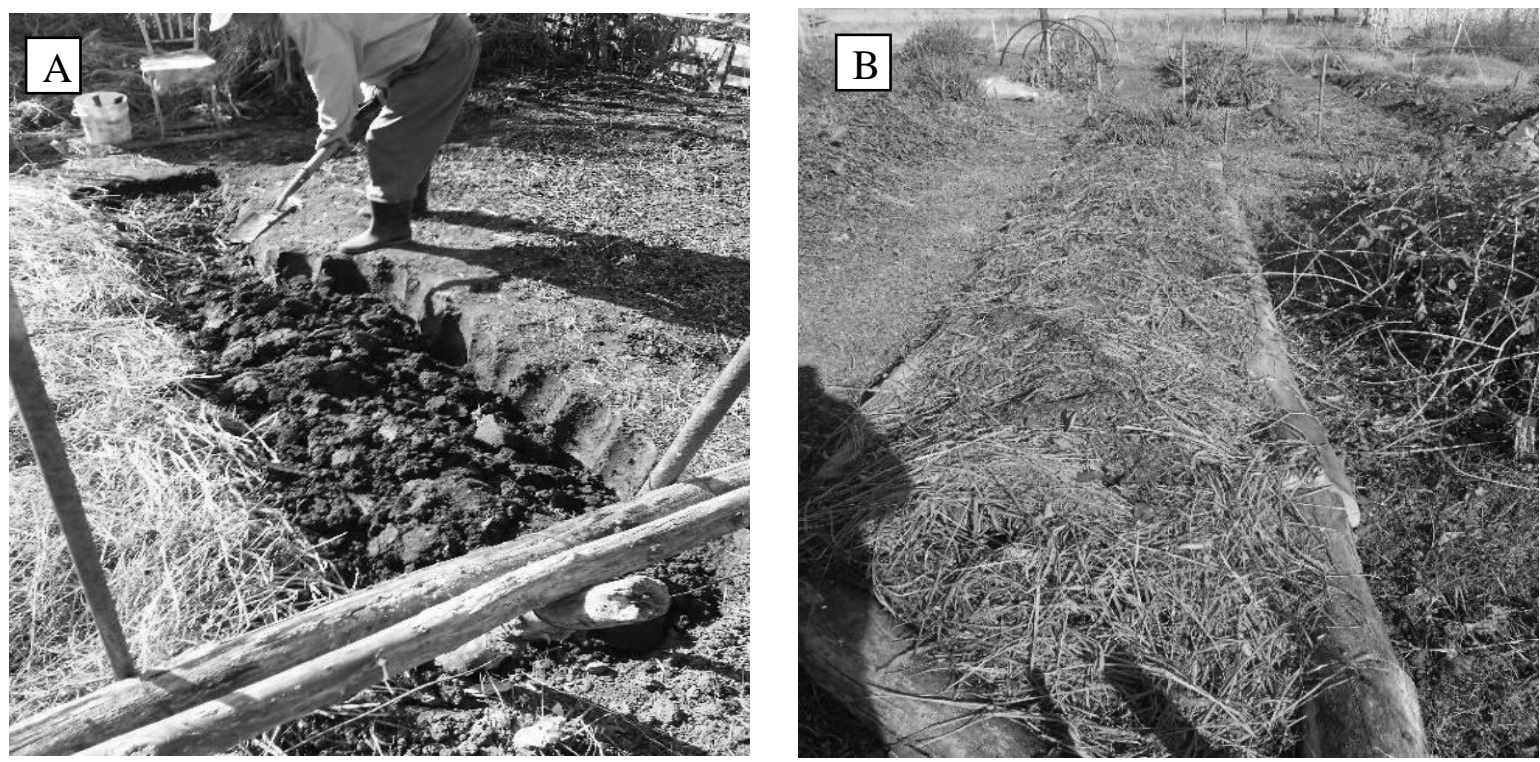

Fotos: Ricardo Edson Salles.

O agricultor A5 atuava no município de Escobar em unidade coletiva envolvendo quatro famílias, que trabalhavam em conjunto e se revezavam nas diversas atividades, compartilhando os resultados da produção. Desenvolviam suas atividades com base na agricultura biodinâmica, com uso de diversas plantas de cobertura, com destaque para sorgo, nabo forrageiro e aveia preta, obtendo estruturação adequada do solo que permitia utilizar menos intensivamente máquinas e implementos. Os produtos eram comercializados em restaurantes de Buenos Aires, e diretamente na unidade de produção, onde faziam regularmente uma feira para consumidores da vizinhança e outras eventuais.

"[...] desarrollamos especies con alto valor de mercado, básicamente alcachofra e acelga roja, para un mercado selecto de comedores y clientes seleccionados, eso nos da la garantía de poder producir conforme a los preceptos de la biodinâmica [...]" (Agricultor A5).

O agricultor A6, de origem boliviana, situava-se no município de "La Matanza", e cultivava aveia preta no inverno como planta de cobertura do solo em áreas de pousio, incorporando-a mecanicamente para o cultivo de hortaliças. Caracterizava-se como um agricultor familiar bem estruturado em termos de instalações e maquinários, que relatou desejo de não utilizar adubos sintéticos e agrotóxicos e adotar manejo menos intensivo no 
uso de agroquímicos. Relatou que percebia essa necessidade a partir da cobrança de consumidores e que estava aberto a experimentos que comprovassem resultados de praticas agroecológicas desenvolvidas pelo INTA. Era um agricultor que exercia liderança na comunidade local, organizando comércio no mercado municipal.

\footnotetext{
“[...] se percibe la necesidad de mejorar las prácticas agrícolas, disminuir el uso de agroquímicos, por cuenta de los clientes que se preguntan si tiene contaminación. Estamos dispuestos a ceder un área para el INTA para probar nuevas prácticas y ayudarnos y también a nuestra comunidad a implementar mejoras en la producción [...]" (Agricultor A6).
}

$\mathrm{O}$ agricultor $\mathrm{A} 7$, também de origem boliviana, tinha sua área no município de "Escobar", onde desenvolvia atividades de produção familiar em conjunto com quatro irmãos. Relatou que utilizava aveia preta como planta de cobertura em pré-cultivo de inverno, incorporando-a mecanicamente na sequência para o cultivo das hortaliças. Declarou ter observado que a prática proporcionava melhor infiltração e retenção de água no solo respectivamente nos períodos mais chuvosos e secos, acrescentando que a partir da atuação do INTA passou a cuidar da produção de forma a minimizar o uso de agrotóxicos, abrindo-se para novas práticas.

\footnotetext{
“[...] anteriormente utilizaba bromuro de metilo para desinfección de los canteros de hortalizas en invernaderos, pero que, por orientación de los técnicos del INTA, sustituyó esa técnica por la plastilina [...] (Agricultor A7).
}

\section{ANÁliSE COMPARADA DAS EXPERIÊNCIAS COM USO DE PLANTAS DE COBERTURA DE SOLO EM Nova Friburgo - RJ (Brasil) e na Área Metropolitana de Buenos Aires - AMBA (ARGENTINA)}

O tempo médio de experiência com o uso de plantas de cobertura de solo pelos agricultores de Nova Friburgo e Área Metropolitana de Buenos Aires (AMBA) era semelhante, respectivamente 2,9 e 2,7 anos, mas com dinâmicas distintas no processo de adoção dessa prática.

Verificou-se em ambos locais que o uso de plantas de cobertura de solo foi fortemente induzido pela ação de técnicos de instituições públicas de pesquisa e desenvolvimento tecnológico. No Brasil, a grande maioria dos entrevistados (93\%) declarou que a ação da Embrapa foi determinante para a adoção da prática em questão, DOI: http://dx.doi.org/10.22295/grifos.v31i56.6034 | Edição Vol. 31, Núm. 56, 2022. 
especialmente por apresentar seus benefícios para o solo e os cultivos de hortaliças em demonstrações práticas.

$\mathrm{Na}$ Argentina observou-se fato semelhante, tendo sido ressaltado por $83 \%$ dos entrevistados, a importância do trabalho do INTA para a inserção da tecnologia em seus sistemas de cultivo de hortaliças. No caso, verificou-se ainda o relato de $50 \%$ dos entrevistados sobre a importância do conhecimento tradicional de seus ancestrais sobre as plantas de cobertura, incluindo repasse de material genético através das gerações e saber específico associado a variedades mais adequadas. Para os agricultores brasileiros essa mesma observação abrangeu apenas $7 \%$ dos entrevistados.

A análise da Tabela 1 indica atenção diferenciada dos agricultores argentinos entrevistados no que tange a redução do aporte de insumos externos. Isso decorre de que o uso de plantas de cobertura estava associado a uma mudança dos sistemas de produção em contexto de processo de transição agroecológica, em que passaram também a evitar agroquímicos sintéticos e aumentaram o preparo e uso de compostagem em suas unidades de produção.

No Brasil, por sua vez, verificou-se que apenas $7 \%$ dos que utilizavam plantas de cobertura evitavam o uso de agroquímicos sintéticos, caracterizando-se a mudança tecnológica em questão com mais pontual e restrita a estratégia de manejo de solo. Isso apesar de $65 \%$ dos entrevistados relatar que o uso de plantas de cobertura de solo de forma continuada reduzia a demanda por fertilizantes e agrotóxicos.

Tabela 1. Características e estratégias gerais de produção relacionadas ao uso de plantas de cobertura de solo, destacadas pelos agricultores entrevistados na Área Metropolitana de Buenos Aires (AMBA), Argentina, e Nova Friburgo - RJ, Brasil (\% de entrevistados).

\begin{tabular}{llcc}
\hline Característica & Estratégia* & AMBA & Nova Friburgo \\
\hline Origem das sementes & Produz & 33 & 7 \\
\cline { 2 - 4 } & Compra & 92 & 100 \\
\hline \multirow{2}{*}{ Manejo da palhada } & Cobertura & 83 & 47 \\
\cline { 2 - 4 } & Incorporada & 83 & 93 \\
\hline Produção de insumos & Mudas & 75 & 47 \\
\cline { 2 - 4 } & Composto & 75 & 20 \\
\hline Sistema de cultivo & Convencional & 25 & 93 \\
\cline { 2 - 4 } & Orgânico & 75 & 7 \\
\hline
\end{tabular}

Fonte: pesquisa de campo.

*Respostas não excludentes. 
Sobre a supressão de plantas espontâneas, constatou-se que na Argentina $65 \%$ dos agricultores relataram perceber melhorias, e no Brasil, $75 \%$ relataram que o uso de plantas de cobertura foi positivo nesse sentido.

No que se refere ao impacto do uso de plantas de cobertura de solo sobre o manejo fitossanitário, no Brasil o relato de $25 \%$ dos agricultores associou uma menor incidência de problemas fitossanitários à maior presença de inimigos naturais em decorrência da prática em questão. Com outra percepção, $10 \%$ dos entrevistados identificaram efeito negativo, associando a presença da palhada no solo ao surgimento de lesmas, principalmente em lavouras no período com mais chuva (verão). Entende-se essa percepção diferenciada como consequência do período de plantio estendido de março a novembro, e das diferentes formas de manejo das plantas de cobertura utilizados em Nova Friburgo - RJ, conforme relatado anteriormente.

Verificou-se entre os agricultores argentinos que o preparo manual do solo era comum e utilizado por $60 \%$ dos entrevistados, sendo a única forma utilizada por $33 \%$. No Brasil, por sua vez, $100 \%$ dos entrevistados recorriam a motomecanização para o preparo do solo, utilizando equipamentos próprios $(50 \%)$ ou alugados $(50 \%)$, sendo o preparo do solo manual utilizado apenas excepcionalmente em áreas muito íngremes ou com a presença de pedras.

Entende-se que a apropriação mais expressiva de práticas agroecológicas, observada junto aos agricultores argentinos, estava relacionada ao fato de que o processo de transferência de tecnologia foi associado a um programa nacional de governo: "ProHuerta", capitaneado pelo INTA, com propostas de ação sistêmica, que preconizava fundamentos específicos, envolvendo desde a transferência de tecnologias que apoiassem a produção de alimentos sem o uso de agrotóxicos, até ações de articulação e promoção de estratégias locais de comercialização e de novos hábitos de consumo. A base do programa era a capacitação progressiva, a participação solidária e o acompanhamento sistemático das ações de campo. (QUEIROZ et al., 2018).

No Brasil o processo de adoção do uso de plantas de cobertura nos sistemas de rotação de cultivo de hortaliças ocorreu vinculado à ação que visou promover a transição agroecológica com foco restrito a questões tecnológicas, notadamente o uso da prática do plantio direto. Essa ação ocorreu capitaneada por grupo sociotécnico interinstitucional que se formou no município de Nova Friburgo desde 2011, quando fortes chuvas ocorridas no DOI: http://dx.doi.org/10.22295/grifos.v31i56.6034 | Edição Vol. 31, Núm. 56, 2022. 
mês de janeiro determinaram aquela que tem sido considerada a pior tragédia ambiental da história do Brasil ${ }^{4}$ (ANTONIO et al., 2019). Esse entendimento acerca da dinâmica dos processos de transição agroecológica, nos dois locais estudados, é reforçado por fator determinante na abordagem da sustentabilidade na agricultura e busca pela autonomia de seus processos produtivos, como a capacidade de produção de sementes na unidade de produção, maior entre os agricultores argentinos, comparativamente com os brasileiros (Tabela 1).

O esforço para a produção de sementes na unidade de produção é uma ação importante para a sustentabilidade dos sistemas produtivos, contribuindo para sua autonomia. Tal comportamento é a maneira mais eficaz de redução da erosão genética vegetal, pois uma agricultura produtiva sustentável depende da agrobiodiversidade e, para sua conservação, é importante reconhecer a importância das populações locais (BEGOSSI, 2011; TOLEDO e BARRERA-BASSOLS, 2009).

Verificou-se que na Argentina os agricultores entrevistados tinham entendimento mais claro da necessidade de avançar com a transição agroecológica em seus sistemas de produção, visando a sustentabilidade. Para eles questões relacionadas à conservação ambiental, da biodiversidade, dos conhecimentos tradicionais e das culturas locais, tinham valor diferenciado, particularmente no que tange a importância da produção de sementes. Segundo Amorozo (2013), agricultores que têm a agricultura como prática para sua subsistência, são pesquisadores locais que possuem conhecimentos e práticas de grande profundidade sobre o manejo e a condução de processos de domesticação de variedades.

No contexto produtivo analisado na Argentina, os conhecimentos relacionados as sementes, assim como os relacionados ao uso de plantas de cobertura, estavam inseridos em dinâmica de transição agroecológica em perspectiva sistêmica de, em sua maioria, sistemas orgânicos de produção de base agreoecológica. No Brasil, diferentemente, a inserção do uso de plantas de cobertura nos sistemas de produção analisados, ocorreu para atender

\footnotetext{
4 "Na madrugada do dia 12 de janeiro de 2011 ocorreram fortes chuvas na região Serrana do Rio de Janeiro que resultaram no que vem sendo considerado como o maior desastre climático ocorrido no Brasil. (...) Estas chuvas resultaram em enchentes e deslizamentos que atingiram áreas rurais e urbanas, comunidades de baixo e de alto poder aquisitivo, algumas ficando totalmente isoladas, destruindo prédios e habitações, infraestrutura pública (...) As principais atividades econômicas da região foram prejudicadas, como indústrias, pecuária, agricultura e comércio (...) Em termos de consequências humanas foram registrados 918 óbitos, 8.795 desabrigados e 22.604 desalojados, resultando no impacto direto sobre a vida de mais de 32 mil habitantes, principalmente nos municípios de Petrópolis, Teresópolis e Nova Friburgo, com o total de sete municípios decretando estado de calamidade pública." (FREITAS et al., 2012, p.1581)
}

DOI: http://dx.doi.org/10.22295/grifos.v31i56.6034 | Edição Vol. 31, Núm. 56, 2022. 
demanda de recuperação e conservação de solo após tragédia ambiental, momento em que parte das áreas de produção foi soterrada ou alagada, e os agricultores passaram a perceber a necessidade de cuidados específicos para a conservação dos solos dos ambientes de montanha locais.

Resultados de pesquisa e experiências produtivas exitosas anteriores na região, com o uso de plantas de cobertura de solo nas rotações de cultivo de hortaliças, basearam o estabelecimento inicial de algumas dinâmicas inovadoras nos espaços agrícolas locais, com destaque para o uso da aveia preta (ANTONIO et al., 2019). A adoção desta como planta de cobertura pelos agricultores deveu-se a sua adaptabilidade às condições locais (BARRADAS et al., 2001) e pela facilidade para os agricultores ajustarem seu uso nas rotações locais de cultivo de hortaliças (ASSIS et al., 2019).

Verificou-se junto aos agricultores entrevistados a percepção de que, nas áreas afetadas por soterramento ou alagamentos, o uso da aveia preta como planta de cobertura é uma estratégia adequada para recuperação dos solos, promovendo sua (re)estruturação. Isso da mesma forma que Assis et al. (2012), ao relatarem que o uso de cobertura morta de aveia preta na produção de hortaliças em Nova Friburgo favoreceu a conservação de estradas vicinais, além de aumentar a produtividade e a qualidade da produção, em especial da couve flor, referendando relato anteriormente citado de redução da incidência da hérnia das crucíferas.

De acordo com Aquino et al. (2014), essa percepção dos agricultores em Nova Friburgo, foi fundamental para que experimentassem e tirassem suas próprias conclusões, com base no "saber fazer", sobre a importância da inserção do uso de plantas de cobertura em seus sistemas de rotações de cultivo de hortaliças.

Assim, no presente estudo verificou-se em Nova Friburgo uma nova base de conhecimentos que motivou a adoção do uso da aveia preta como planta de cobertura pelos agricultores, na medida em que a prática passou a fazer sentido para eles, registrando-se declarações associadas com: "melhoria do solo" (Agricultor B2); "planta mais viçosa" (Agricultor B3); "terra mais fofa" (Agricultor B4); "água limpa" (Agricultor B5) e, principalmente, a observação de que a erosão do solo diminuiu com o uso da aveia preta, qualificada a partir do relato de $67 \%$ dos agricultores entrevistados que observaram melhoria nas estradas que passaram a ter menor custo de manutenção. 
Em acréscimo, a inserção do uso de plantas de cobertura do solo valorizou a paisagem agrícola regional e, apesar de ter sido verificado que ainda havia um intenso manejo mecânico dos solos, a sua manutenção com cobertura na maior parte do tempo reduziu a degradação das áreas de plantio (Figura 3).

$\mathrm{Na}$ Argentina as percepções dos agricultores em relação às melhorias proporcionadas pelo uso de plantas de cobertura do solo foram associadas ao melhor rendimento da irrigação; melhor comportamento da planta em relação a doenças do solo; e minimização da erosão, apesar de com menor ênfase, comparativamente ao verificado no Brasil, em função da condição topográfica plana das áreas de cultivo.

Procurou-se ainda identificar junto aos entrevistados no Brasil e na Argentina, a percepção acerca de indicadores relacionados à melhoria das características gerais das plantas (na colheita) e dos solos, uso de água de irrigação, manejo de plantas espontâneas, e aspectos fitossanitários, em suas unidades de produção, que estivessem associados a efeitos diretos benéficos do uso de plantas de cobertura de solo (Tabela 2).

Verificou-se, nos dois países, um destaque dos entrevistados para os benefícios para o aspecto geral das plantas, determinante para o acesso a mercados, bem como para aspectos de solo, disponibilidade de água para irrigação e demandas de capinas, que influenciam diretamente a sustentabilidade.

Figura 3. Aspecto geral da paisagem com o cultivo de aveia preta com diferentes épocas de plantio em Nova Friburgo.

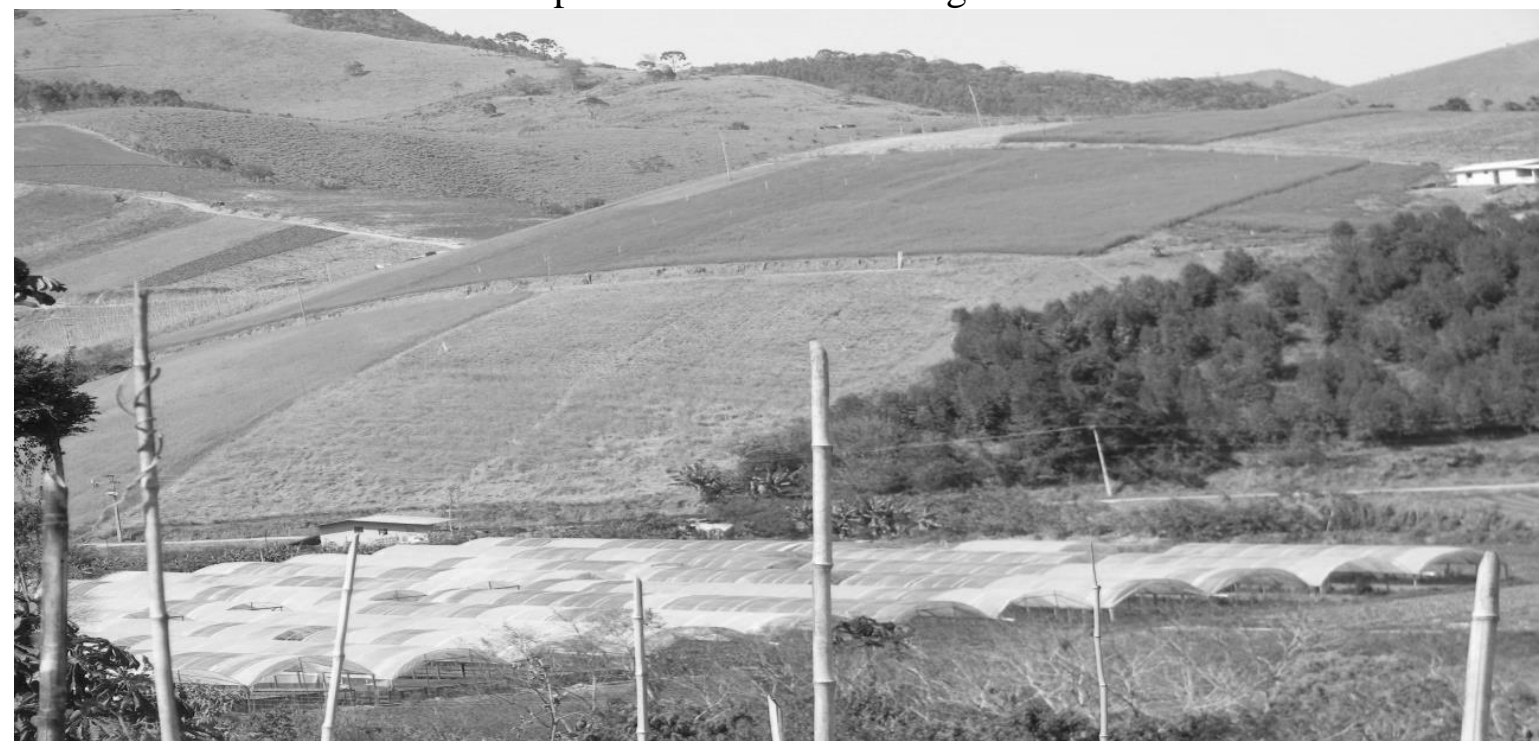

Foto: Renato Linhares de Assis. 
Tabela 2. Indicadores, destacados pelos agricultores entrevistados, relacionados a melhoria das características gerais das plantas (na colheita) e dos solos, uso de água de irrigação, manejo de plantas espontâneas e aspectos fitossanitários, associados a efeitos benéficos do uso de plantas de cobertura de solo em suas unidades de produção na Área Metropolitana de Buenos Aires (AMBA), Argentina, e em Nova Friburgo - RJ, Brasil (\% de entrevistados).

\begin{tabular}{llcc}
\hline Tipo de indicador & Parâmetro & AMBA & Nova Friburgo \\
\hline \multirow{3}{*}{ Plantas na colheita } & Aspecto geral & 61 & 69 \\
\cline { 2 - 4 } & Peso & 38 & 40 \\
\cline { 2 - 4 } & Uniformidade & 26 & 54 \\
\hline \multirow{2}{*}{ Solo } & Umidade & 69 & 77 \\
\cline { 2 - 4 } Água & Erosão & 76 & 76 \\
\hline Plantas espontâneas & Irrigação & 86 & 76 \\
\hline \multirow{2}{*}{ Aspectos fitossanitários } & Capinas & 68 & 78 \\
\hline & Doenças do solo & 71 & 51 \\
\cline { 2 - 4 } & Doenças da folha & 36 & 32 \\
\hline
\end{tabular}

Fonte: pesquisa de campo.

*Respostas não excludentes.

$\mathrm{Na}$ Argentina verificou-se a descrição por parte dos agricultores da contribuição do uso de plantas de cobertura de solo na redução da demanda por mão de obra, associando esse benefício a maior facilidade no manejo do solo, posto que, conforme destacado anteriormente, o preparo manual do solo era prática comum para a maioria dos entrevistados nesse país. No Brasil, por sua vez, registrou-se afirmações dos entrevistados com referência a importância da manutenção do solo coberto para proteção das mudas logo após o transplante.

Por fim, ainda que houvesse a percepção por parte dos entrevistados, em ambos os países, de que a prática analisada contribuía para reduzir a erosão dos solos e economizar água, não se verificou um planejamento rotineiro das rotações de cultivo que possibilitasse o pré-cultivo de plantas de cobertura de solo ao menos uma vez ao ano em todas as áreas de produção.

\section{CONSIDERAÇÕES FINAIS}

Nas duas regiões estudadas no Brasil e Argentina, o esforço sistemático por parte de entidades públicas, de promover junto aos agricultores um entendimento mais aprofundado sobre sistemas de manejo do cultivo de hortaliças que promovam maior conexão com DOI: http://dx.doi.org/10.22295/grifos.v31i56.6034 | Edição Vol. 31, Núm. 56, 2022. 
práticas conservacionistas e sustentáveis, foi determinante em facilitar o caminho para a inserção do uso de plantas de cobertura de solo nos sistemas de produção familiares.

Destaca-se como dificuldades a serem dirimidas para que ocorram maiores avanços no uso de plantas de cobertura solo nas regiões estudadas nos dois países: (i) necessidade do uso de maior diversidade de espécies; (ii) pouca oferta de sementes no comércio de insumos em quantidade e diversidade; (iii) falta de entendimento, por parte dos agricultores, da necessidade do planejamento antecipado das rotações de cultivo, considerando sempre, pelo menos uma vez no ano, a inserção do ciclo de cultivo de uma planta de cobertura de solo.

Nas regiões visitadas no Brasil e Argentina, as dinâmicas de produção hortícola têm dilemas correlatos que demandam ações governamentais e políticas públicas específicas, que apoiem o desenvolvimento e disseminação de soluções que visem melhorar a sustentabilidade da atividade em questão, notadamente as que incentivem localmente o uso, adaptação e identificação de plantas de cobertura que contribuam para o menor revolvimento dos solos na produção de hortaliças.

\section{REFERÊNCIAS}

ALTIERI, M.; LANA, M. A.; BITTENCOURT, H. von H.; VENTURI, M.; KIELING, A. dos S.; COMIN, J. J.; LOVATO, P. E. Aumento do rendimento dos cultivos através da supressão de plantas espontâneas em sistema de plantio direto orgânico em Santa Catarina, Brasil. Rio de Janeiro: Revista Brasileira de Agroecologia, v.7, p.63-71, 2012. Disponível em: 〈https://core.ac.uk/download/pdf/234771298.pdf>. Acesso em 18/11/2020.

AMOROZO, M. C. de M. Perspectivas atuais para a conservação on farm da agrobiodiversidade. In: Sistemas agrícolas de pequena escala e a manutenção da agrobiodiversidade: uma revisão e contribuições. Botucatu: FCA-Unesp, p.97-120, 2013.

ANGELETTI, M. da P.; SOUZA, J. L. de; COSTA, H.; SOUZA, G. S. de; EWALD, M. C.; BREMEMKAMP, C.; MUNIZ, E. S.; BAHIENSE, D. V. Utilização de espécies vegetais como cobertura de solo no sistema plantio direto e como adubação verde na Região Serrana do ES. Venda Nova do Imigrante: Revista Científica Intelletto, v.1, n.2, p.87-102, $2016 . \quad$ Disponível em: <https://biblioteca.incaper.es.gov.br/digital/bitstream/123456789/2987/1/BRTutilizacaodeespeciesvegetaiscomocoberturadesolonosistemadeplantiodireto-angeletti.pdf $>$. Acesso em 26/09/2021.

ANTONIO, G. J. Y.; ASSIS, R. L. de; AQUINO, A. M. de. The adoption of green manure processes applied to vegetable cultivation systems in mountainous environments of Rio de Janeiro State, Brazil. Berlin: Open Agriculture, v. 4: p.446-451, 2019. Disponível em: <https://www.degruyter.com/view/journals/opag/4/1/article-p446.xml >. Acesso em: 04/01/2020. 
AQUINO, A. M. de; ASSIS, R. L. de; FERREIRA, M. S. T.; PEREIRA, M. DA S.; TEIXEIRA, O. A. Disseminação da aveia-preta como cobertura do solo em sistemas de cultivo de hortaliças em unidades de produção familiar na Região Serrana Fluminense. In: CONGRESSO DA SOCIEDADE BRASILEIRA DE SISTEMAS DE PRODUÇÃO, 10., 2014, Foz do Iguaçu. Anais... Foz do Iguaçu: Sociedade Brasileira de Sistemas de Produção, 2014.

ASSIS, R. L. de; ANTONIO, G. J. Y.; AQUINO, A. M. de. Ambientes de montanha: experiência de desenvolvimento endógeno e agricultura na Região Serrana do estado do Rio de Janeiro (Brasil). Tunja: Cultura Científica, v.17: p.10-17, 2019. Disponível em: <file:///C:/Users/RenatoLinhares/Downloads/591-Texto\%20del\%20art\%C3\%ADculo1787-1-10-20200127\%20(4).pdf> Acesso em 04/01/2020.

ASSIS, R. L.; AQUINO, A. M. Pesquisa participativa na Região Serrana Fluminense experiência do Núcleo de Pesquisa e Treinamento para Agricultores da Embrapa em Nova Friburgo. In: PRADO, R. B.; TURETTA, A.P.D.; ANDRADE, A.G. (ed.). Manejo e conservação do solo e da água no contexto das mudanças ambientais. Rio de Janeiro: Embrapa Solos, p.239-253, 2010.

ASSIS, R. L. de; AQUINO, A. M. de; GUERRA, J. G. M.; MADEIRA, N.; TEIXEIRA, O.; SILVA, M.; RISSO, I. A. M Experiências e estratégias na inserção da adubação verde em sistemas de cultivo de hortaliças na Região Serrana Fluminense. Seropédica: Embrapa Agrobiologia, 20124 p. (Embrapa Agrobiologia. Circular técnica, 32).

BARRADAS, C.A.A.; FREIRE, L. R.; DE ALMEIDA, D. L.; DE POLLI, H. Comportamento de adubos verdes de inverno na região serrana fluminense. Brasília: Pesquisa Agropecuária Brasileira, v.36, n.12, p.1461-1468, 2001.

BEGOSSI, A. Resiliência e populações neotradicionais. In: DIEGUES, A. C. S.; MOREIRA A. C. C. (ed.). Espaços e recursos naturais de uso comum. São Paulo: NUPAUB/USP, p.205-236, 2011. Disponível em: 〈http://nupaub.fflch.usp.br/sites/nupaub.fflch.usp.br/files/color/Espacos_UsoComum.pdf> Acesso em: 19/11/2020.

FREITAS, C. M. de; CARVALHO, M. L. de; XIMENES, E. F.; ARRAES, E. F.; GOMES, J. O. Vulnerabilidade socioambiental, redução de riscos de desastres e construção da resiliência: lições do terremoto no Haiti e das chuvas fortes na Região Serrana, Brasil. Ciênc. Rio de Janeiro: Saúde Coletiva, v.17, n.6, 2012. Disponível em: <https://www.scielo.br/pdf/csc/v17n6/v17n6a21.pdf $>$. Acesso em: 19/11/2020.

GRISEL, P.-N.; ASSIS, R. L. de. Condicionantes agroeconômicos para adoção de práticas sustentáveis em ambientes de montanha em Nova Friburgo (RJ). Sinop: Nativa, v.8, n.5, p.687-697, 2020. Disponível em: <https://periodicoscientificos.ufmt.br/ojs/index.php/nativa/article/view/10012>. Acesso em: $10 / 11 / 2020$.

LE GALL, J.; GARCÍA, M. Reestructuraciones de las periferias hortícolas de Buenos Aires y modelos espaciales ¿Un archipiélago verde? Paris: EchoGéo. v.11, p.1-12, 2010. Disponível em: <https://journals.openedition.org/echogeo/11539>. Acesso em: 18/11/2020. 
QUEIROZ, M. A.; GUEDES, C. A. M.; ASSIS, R. L. de. A atuação dos voluntários do programa ProHuerta em Río Cuarto (Córdoba, Argentina) na formação de hortas e difusão dos conceitos de agricultura orgânica e agroecologia. La Plata: Revista de la Facultad de Agronomía. v.117, p.43-52, 2018.

REDIN, M.; GIACOMINI, S. J.; FERREIRA, P. A. A.; ECKARDT, D. P. Planas de cobertura de solo e agricultura sustentável: espécies, matéria seca e ciclagem de carbono e nitrogênio. In: Tiecher, T. (ed.). Manejo e conservação do solo e da água em pequenas propriedades rurais no sul do Brasil: práticas alternativas de manejo visando a conservação do solo e da água. Porto Alegre: UFRGS, p.7-22, 2016. Disponível em: <http://www.agrisus.org.br/arquivos/livro_RGS.pdf>. Acesso em: 16/09/2021.

SECRETARIA DE AGRICULTURA E PECUÁRIA DO ESTADO DO RIO DE JANEIRO (SAP-RJ). Agricultura Emergência. Niterói, 2011, 21 p. mimeo. SAP-RJ.

SILVA HIRATA, A. C.; HIRATA, E. K.; MONQUERO, P. A.; GOLLA, A. R. Plantas de cobertura no controle de plantas daninhas na cultura do tomate em plantio direto. Viçosa: Planta Daninha, v.27, n.3, p.465-472, 2009. Disponível em: <https://www.scielo.br/pdf/pd/v27n3/06.pdf >. Acesso em: 18/11/2020.

SMITH, J.; RATTA, A.; NASSR, J., Urban agriculture: food, jobs and sustainable cities. New York: United Nations Development Programme, 1996. 302 p. (Publication Series for Habitat II, v. 1).

TOLEDO, V. M.; BARRERA-BASSOLS, N. A memória biocultural: a importância ecológica das sabedorias tradicionais. São Paulo: Expressão Popular, 2015, 225p.

VALMORBIDA, J.; WAMSER, A. F.; SANTIN, B. L.; ENDER, M. Métodos de manejo e plantas de cobertura do solo para o cultivo do tomateiro tutorado. Florianópolis: Agropecuária Catarinense, v.33, p.76-81, 2020. Disponível em: <https://publicacoes.epagri.sc.gov.br/RAC/article/view/753/942>. Acesso em: 26/09/2021.

YIN, Robert K. Estudo de caso: planejamento e métodos. Porto Alegre: Bookman, 2001. 205p. 